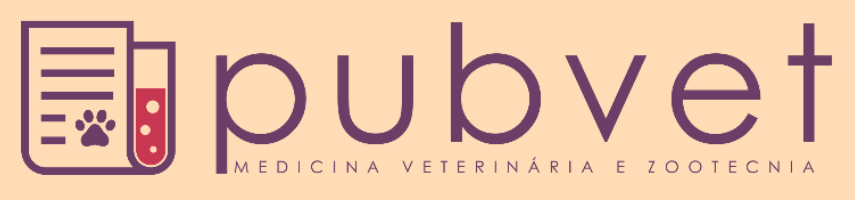

https://doi.org/10.31533/pubvet.v13n3a297.1-9

\title{
Termografia de capivaras (Hydrochoerus hydrochaeris) do perímetro urbano de Campo Grande-MS
}

\author{
Lucas Gomes da Silva ${ }^{1 *} \bullet$, Nickson Milton Corrêa Siqueira ${ }^{1} \bullet$, Danaila Bruneli Fernandes \\ Gama $^{1}$, João Victor de Souza Martins ${ }^{2}{ }^{\circ}$, Rafael de Oliveira Lima ${ }^{2}$, Larissa Venier de \\ Oliveira $^{3}{ }^{\circ}$, Rodrigo Gonçalves Mateus ${ }^{\circ}{ }^{\circ}$, Paula Helena Santa Rita ${ }^{4} \bullet$ \\ ${ }^{1}$ Acadêmico de Medicina Veterinária da Universidade Católica Dom Bosco. Campo Grande - MS Brasil. \\ ${ }^{2}$ Acadêmico de Zootecnia da Universidade Católica Dom Bosco. Campo Grande - MS Brasil. \\ ${ }^{3}$ Médica Veterinária autônoma. Campo Grande-MS Brasil. \\ ${ }^{4}$ Professor Doutor da Universidade Católica Dom Bosco. Campo Grande - MS Brasil. \\ *Autor de correspondência:_lucas_gomes_09@homail.com
}

Resumo. O objetivo desse estudo foi à obtenção de imagens termográficas de capivaras que habitam áreas urbanas com intuito de se obter diagnósticos iniciais sem que haja contato direto com estas, não interferindo no conforto e bem-estar dos animais, além de não provocar alterações em seu comportamento diário. A câmera utilizada termográfica modelo Flir SC620 onde capturou imagens de diferentes animais tanto individuais como em grupo, sendo classificados, quando individuais, como machos e fêmeas, adultos ou filhotes e animais em grupos. Grupo analisado foi de um total de 25 animais situados no Parque das Nações Indígenas, localizado no centro urbano da cidade de Campo Grande MS no mês de novembro de 2017. As imagens foram capturadas às 17 horas, com temperatura local de $28{ }^{\circ} \mathrm{C}$ e umidade relativa do ar em $80 \%$. Foram analisadas áreas como, corpo e cabeça, onde foram subdividas em articulações, regiões específicas com indicações pontuais em aumento de temperatura local, olhos e boca e linhas tracejadas pelo corpo para média dos membros, corpo em região lombar e cabeça. Pela maneira como foram usados a termografia, de forma não invasiva, os níveis de estresse foram muito baixos e a redução do tempo também foi bem significante. Constatou-se que os níveis de estresse foram baixos e que os animais puderam assim mantiver seus hábitos normalmente. Os machos apresentaram um significante aumento de temperatura na região onde está localizada a glândula supranasal em relação ao resto do corpo, já nas fêmeas as regiões de maior calor foram na região ocular, igualando-se aos machos nas regiões de conduto auricular. Os filhotes apresentaram temperaturas maiores quando comparadas aos animais adultos, provavelmente por apresentarem um metabolismo maior por conta da sua maior demanda energética. Este trabalho mostra a eficiência da metodologia para diminuir o manejo com esses animais, não alterando o seu bem-estar e sua homeostasia. Com isso, verifica-se que as imagens podem nos auxiliar para identificação de patologias, número de animais em um lote, procura de animais em locais de difícil acesso e classificação de macho ou fêmea, nos auxiliando tanto em exames clínicos individuais como análises em grupo dos mesmos.

Palavras chave: animais silvestres, temperatura de superfície, diagnóstico diferencial

\section{Capybara's (Hydrochoerus hydrochaeris) thermography of urban perimeter of Campo Grande-MS}

Abstract. The objective of this study was to obtain thermographic images of capybaras that inhabit urban areas with the purpose of obtaining initial diagnoses without direct 
contact with them, not interfering with the comfort and well-being of the animals, besides not provoking changes in their daily behavior. The camera used thermographic model Flir SC620 where captured images of different animals both individual and in groups, being classified, when individual, as males and females, adults or puppies and animals in groups. The analyzed group was of a total of 25 animals located in the "Parque Das Nações Indígenas", located in the urban center of the city of Campo Grande - MS in the month of November of 2017. The images were captured at 17 hours, with local temperature of $28^{\circ} \mathrm{C}$ and relative humidity of $80 \%$. Areas such as body and head were analyzed, where they were subdivided into articulations, specific regions with specific indications of increased local temperature, eyes and mouth and dashed lines from the body to the limbs, body in the lumbar region and head. Due to the way non-invasive thermography was used, the stress levels were very low and the time reduction was also very significant. It was found that the levels of stress were low and that the animals could thus maintain their habits normally. The males showed a significant increase in temperature in the region where the supranasal gland is located in relation to the rest of the body, whereas in the females the regions of greater heat were in the ocular region, being equal to the males in the regions of the atrial conduit. The pups presented higher temperatures when compared to the adult animals, probably because they present a higher metabolism due to their greater energy demand. This work shows the efficiency of the methodology to reduce the handling with these animals, not altering their well being and their homeostasis. With this, it can be verified that the images can help us to identify pathologies, number of animals in a batch, search of animals in places of difficult access and classification of male or female, assisting us in both individual clinical examinations and group analyzes of the same.

Keywords: wild animals, surface temperature, differential diagnosis

\section{Termografía de capibaras (Hydrochoerus hydrochaeris) del perímetro urbano de Campo Grande-MS}

Resumen. El objetivo de este estudio fue la obtención de imágenes termográficas de capibaras que habitan áreas urbanas con el propósito de obtener diagnósticos iniciales sin que haya contacto directo con éstas, no interfiriendo en el confort y bienestar de los animales, además de no provocar alteraciones en el ambiente su comportamiento diario. La cámara termográfica modelo Flir SC620 utilizada capturó imágenes de diferentes animales tanto individuales como en grupo, siendo clasificados, cuando individuales, como machos y hembras, adultos o crías y animales en grupos. El grupo analizado fue de un total de 25 animales situados en el Parque de las Naciones Indígenas, ubicado en el centro urbano de la ciudad de Campo Grande - MS en el mes de noviembre de 2017. Las imágenes fueron capturadas a las 17 horas, con temperatura local de $28^{\circ} \mathrm{C}$ y humedad relativa del aire en un $80 \%$. Se analizaron áreas como, cuerpo y cabeza, donde fueron subdividas en articulaciones, regiones específicas con indicaciones puntuales en aumento de temperatura local, ojos y boca y líneas discontinuas por el cuerpo para media de los miembros, cuerpo en región lumbar y cabeza. Por la manera como se utilizaron la termografía, de forma no invasiva, los niveles de estrés fueron muy bajos y la reducción del tiempo también fue muy significativa. Se constató que los niveles de estrés fueron bajos y que los animales pudieron así mantener sus hábitos normalmente. Los machos presentaron un significante aumento de temperatura en la región donde está localizada la glándula supra nasal con relación al resto del cuerpo, ya en las hembras las regiones de mayor calor fueron en la región ocular, igualando a los machos en las regiones de conducto auricular. Los cachorros presentaron temperaturas mayores cuando se compararon con los animales adultos, probablemente por presentar un metabolismo mayor debido a su mayor demanda energética. Este trabajo muestra la eficiencia de la metodología para disminuir el manejo con esos animales, no alterando su bienestar y su homeostasia. Con ello, se verifica que las imágenes pueden ayudarnos a identificar patologías, número de animales en un lote, búsqueda de animales 
en lugares de difícil acceso y clasificación de macho o hembra, ayudándonos tanto en exámenes clínicos individuales como análisis en grupo de estos.

Palabras clave: animales silvestres, temperatura superficial, diagnóstico diferencial

\section{Introdução}

A capivara Hydrochoerus hydrochaeris é o maior roedor do mundo, podendo chegar a $100 \mathrm{~kg}, 134$ $\mathrm{cm}$ de comprimento, $62 \mathrm{~cm}$ de altura e com 4 dedos dianteiros e 3 traseiros. Entre esses dedos apresentam uma membrana a qual facilita o seu desenvolvimento aquático em fuga (Furlan \& Milko, 2008) Os machos da espécie apresentam uma glândula sebácea de cor escura na parte superior da cabeça com células secretoras que expelem um líquido branco e de consistência pegajosa a fim de marcar território ou atrativo para as fêmeas (Alho et al., 1987; Alho \& Cleber, 1986).

$\mathrm{O}$ aumento da tecnologia gerou meios de diagnósticos mais avançados permitindo que o médico veterinário realize diagnósticos cada vez mais eficientes (Lahiri et al., 2012) como a termografia, sendo uma forma de conversão da radiação térmica em imagens com a temperatura detalhada do corpo do animal (Ferreira et al., 2016; Mikail, 2010).

A temperatura é um importante indicador do bem-estar animal e com a termografia é um indicador de estresse assim como de doenças circulatórias e musculares sem a necessidade de métodos invasivos (Roberto \& Souza, 2014). De um modo geral, em casos que se realiza um único exame, o indicado é que o profissional realize o exame comparando a superfície com suspeita de lesão com a mesma região contralateral (Brioschi et al., 2003). É importante ressaltar o fato do exame termográfico em animais silvestres não ser invasivo, não haver necessidade de imobilização, não apresentar radiação e poder ser usado tantas vezes forem necessárias, tantos em animais silvestres adultos, jovens e gestantes. $\mathrm{O}$ fato de a termografia ser totalmente indolor aumenta ainda mais o leque de possibilidades da realização do exame, principalmente em casos mais complexos que exijam a imobilização do animal ou procedimentos realizados dentro da própria clinica pelo médico veterinário responsável (Silva et al., 2013). Com o aumento de temperatura é indicado uma inflamação e vaso dilatação, quando a temperatura diminui em certo ponto é indicativo de dor local, edema, trombose vascular ou infarto de tecido, formando na câmera uma área de diminuição de temperatura contornada por emissões térmicas aumentadas devido ao desvio vascular (Silva et al., 2013).

O objetivo do trabalho foi obtenção de imagens termográficas de capivaras que habitam áreas urbanas com intuito de se obter diagnósticos iniciais sem que haja contato direto com estas, não interferindo no conforto e bem-estar dos animais, além de não provocar alterações em seu comportamento diário.

\section{Material e métodos}

As avaliações foram realizadas no Parque das Nações Indígenas, localizado no centro urbano da cidade de Campo Grande, Mato Grosso do Sul no mês de novembro de 2017, sendo o mesmo considerado um ambiente turístico, onde a convivência das capivaras com os seres humanos é extremamente comum e significativa.

Foram capturadas imagens de um grupo de 25 animais que se encontravam próximo à mata presente no parque onde havia animais de diferentes faixas etárias e sexo. As capivaras foram avaliadas sem interferência em seus hábitos comportamentais. As capturas das imagens foram realizadas em uma distância a modo a não interferir em sua vida natural, preservando-se as condições do bem-estar animal. O período das coletas de imagem ocorreu às 17 horas, no qual está de acordo com o horário de maior movimentação dos animais no parque em relação às pessoas que frequentam, utilizando uma câmera termográfica modelo Flir SC620 capturando imagens de diferentes animais de modo individual e em grupo, sendo classificados como machos e fêmeas, adultos ou filhotes.

As imagens foram analisadas com o software Flir QuickReport 1.2 SP2, com temperatura local de $28^{\circ} \mathrm{C}$ e umidade relativa do ar em $80 \%$ e valor de emissividade utilizou-se como padrão 0,98 . O diagnóstico dos animais no software seguiu padrões considerando a área total dos animais e área separada em quadrantes, sendo assim, membros, corpo e cabeça, onde foram subdividas em articulações, 
regiões específicas com indicações pontuais em aumento de temperatura local, olhos e boca e linhas tracejadas pelo corpo para medida dos membros, corpo em região lombar e cabeça. As imagens foram padronizadas com referências aos membros anteriores e posteriores, olhos, glândula supranasal, conduto auricular e área animal, para seguintes comparações entre os diferentes animais.

Com relação ao grupo de animais foi analisada a quantidade de animais em um lote por diferença de temperatura, localização de animais dentro de matas e em algumas imagens a definição de macho e fêmeas em longa distância.

As mensurações de temperatura corporal foram analisadas seguindo os pontos de conduto auricular e olhos, assim levando em consideração de acordo com a temperatura de área do animal e imagem.

\section{Resultados e discussão}

Os machos, quais foram passados pela análise de temperatura das imagens com utilização de linhas traçadas, apresentaram uma média de temperatura semelhante em relação ao corpo (segmento Li2 da Figura 1) e aos membros (segmento Li3 e Li4 da Figura 1) e um aumento significativo na cabeça (segmento Li1 da figura 1) em relação aos outros de acordo com a Tabela 1.

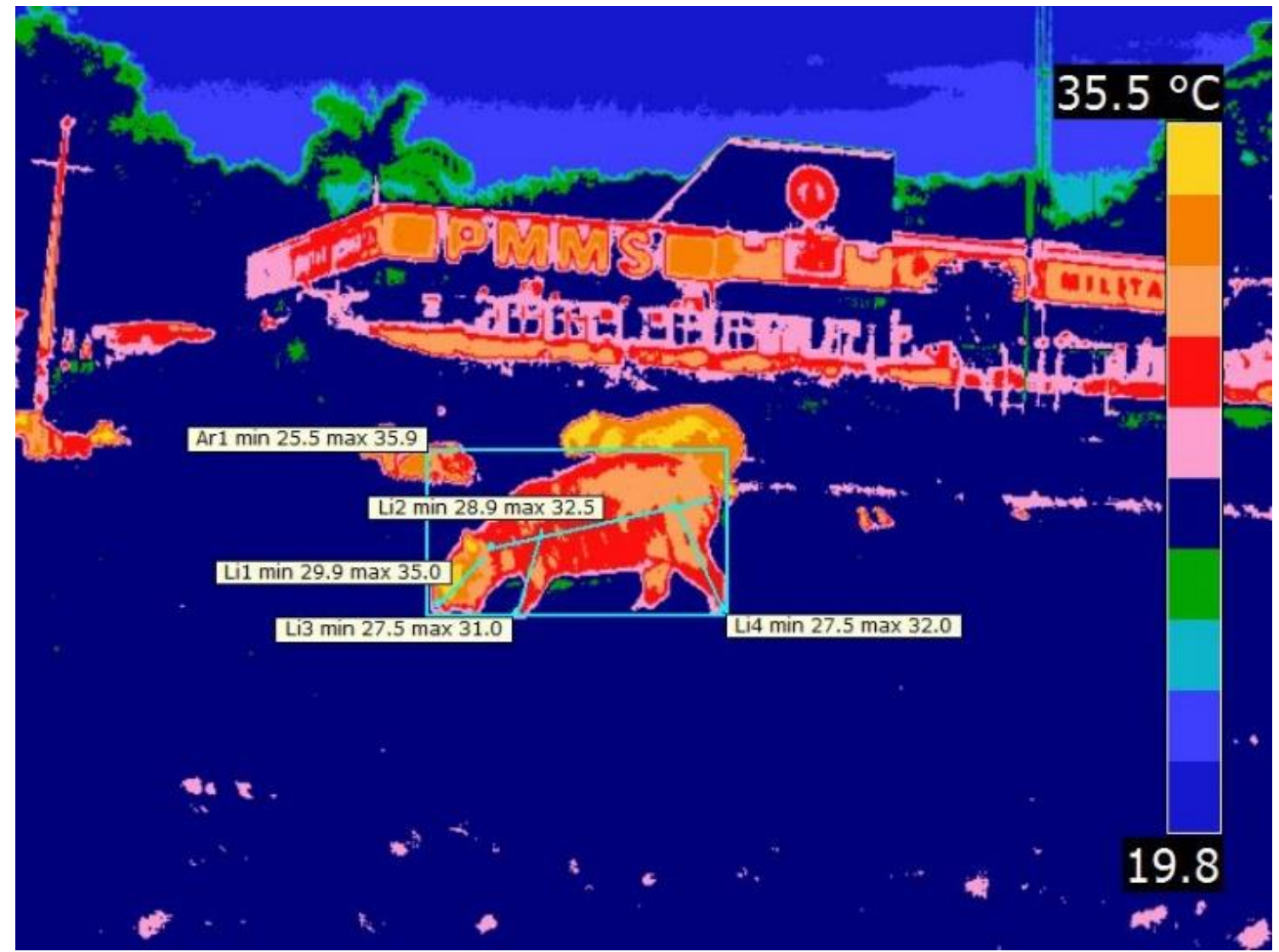

Figura 1. Representação de área total e linhas na termografia médica em capivara do perímetro urbano de Campo Grande, MS.

Tabela 1. Temperatura média da determinação de linhas e quadrantes de capivaras no perímetro urbano de Campo Grande, MS

\begin{tabular}{lccc}
\hline & Mínimo $\left({ }^{\circ} \mathrm{C}\right)$ & Máximo $\left({ }^{\circ} \mathrm{C}\right)$ & Média $\left({ }^{\circ} \mathrm{C}\right)$ \\
\cline { 2 - 4 } Imagem & 20,1 & 36,2 & 30,0 \\
Ar1 - Área animal & 26,2 & 35,9 & 34,1 \\
Li1- Cabeça & 31,4 & 35,5 & 32,1 \\
Li2- Corpo & 30,5 & 33,9 & 32,3 \\
Li3 - MA & 30,1 & 33,9 & 32,5 \\
Li4 - MP & 30,2 & 33,7 & \\
\hline
\end{tabular}

$\mathrm{Ar}$ - área total do animal; $\mathrm{Li}$ - linha; MA - membro anterior; $\mathrm{MP}$ - membro posterior. 
Durante o procedimento verificou-se que os animais não passaram por estresse nenhum, assim como, mantiveram seus hábitos normais durante o manejo. Isso corrobora com Lima et al. (2014) onde a utilização do método não influenciou no bem-estar dos animais e demonstrou seguridade tanto para as capivaras como para o manipulador da câmera. Por ser um método não invasivo, os níveis de estresse são muito baixos e o tempo de manejo também diminui, o que é um problema para aferição nos níveis vitais de acordo com Batista et al. (2009) em manejo com catetos. Com isso a praticidade do trabalho se torna maior e mais efetiva naqueles animais que realmente apresentam alguma alteração. A diferença de temperatura está relacionada à região que obtém mais pelos e permanece, por este animal ter um hábito aquático, mais tempo molhada. Centurion et al. (2016) relacionam bovinos que em apresentam diferenças na temperatura de acordo com a pelagem do animal e áreas sem pelo, isso pode ser um indicativo onde o animal tricotomizado apresentou um aumento de temperatura.

Nos machos submetidos à determinação de pontos foi identificado um aumento significativo em relação a sua área total onde se localizava a glândula supra nasal e aferições com as regiões mais quentes dos animais onde se localizava o olho e o conduto auditivo do animal, assim distribuindo uma média como representado na tabela 2.

Tabela 2. Temperatura da determinação de pontos em olhos, ouvido e glândula supra nasal de capivaras no perímetro urbano de Campo Grande, MS

\begin{tabular}{lccc}
\hline & Mínima $\left({ }^{\circ} \mathrm{C}\right)$ & Máxima $\left({ }^{\circ} \mathrm{C}\right)$ & Média $\left({ }^{\circ} \mathrm{C}\right)$ \\
\cline { 2 - 3 } Imagem & 23,6 & 36,2 & 28,1 \\
Ar1 - Área animal & 24,1 & 36,2 & \\
Sp1 - Conduto auditivo & 35,8 & & \\
Sp2 - Olho & 35,0 & \\
Sp3 - Glândula supranasal & 34,4 & \\
\hline
\end{tabular}

$\mathrm{Ar}$ - Área total do animal; Sp - ponto representado nos animais.

Como especificado por Centurion et al. (2016), os olhos e o conduto auditivo são os que apresentam menor interferência com pelos e outros materiais, resultando assim, em uma temperatura mais fidedigna em relação às outras. A glândula supranasal apresentou um aumento de temperatura por ser uma glândula sebácea e secretar um material seroso, este material tem uma incidência de temperatura maior, além da glândula não ser recoberta por pêlos ficando mais exposta a câmera.

As fêmeas obtiveram uma temperatura média de área e conduto auricular semelhante aos machos obtendo diferença apenas na temperatura ocular podendo ser observado na comparação entre as tabelas 2 e 3.

Tabela 3. Média da temperatura de área e temperatura pontual de capivaras fêmeas do perímetro urbano de Campo Grande, MS

\begin{tabular}{lccc}
\hline & Mínima $\left({ }^{\circ} \mathrm{C}\right)$ & Máxima $\left({ }^{\circ} \mathrm{C}\right)$ & Média $\left({ }^{\circ} \mathrm{C}\right)$ \\
\cline { 2 - 3 } Imagem & 24,2 & 36,4 & 29,0 \\
Ar1 - Área animal & 24,8 & 36,2 & \\
Sp1 - Conduto auricular & 35,8 & \\
Sp2 - Olho & 35,7 & \\
\hline
\end{tabular}

Ar - Área total do animal; Sp - ponto representado nos animais.

Uma das fêmeas apresentou um aumento de temperatura na região abdominal (Tabela 4) onde se localiza os tetos do animal. De acordo com Digiovani (2014) este pode ser algum indicativo de inflamação nas glândulas mamárias, mas também pode ser resultado de um início de lactação (Figura 2). 
Tabela 4. Fêmea adulta com aumento de temperatura na região abdominal

\begin{tabular}{lccc}
\hline & Mínima $\left({ }^{\circ} \mathrm{C}\right)$ & Máxima $\left({ }^{\circ} \mathrm{C}\right)$ & Média $\left({ }^{\circ} \mathrm{C}\right)$ \\
\cline { 2 - 4 } Imagem & 24,0 & 37,4 & 37,4 \\
Ar1 - Área animal & 24,6 & 35,8 & 29,5 \\
Ar2 - Abdômen & 30,0 & \\
Sp1 - Abdômen & 35,8 & \\
Sp2 - Ouvido & 37,4 & \\
Sp3 - Olho & 36,3 & \\
\hline Ar A A
\end{tabular}

$\mathrm{Ar}$ - Área total do animal; $\mathrm{Sp}$ - ponto representado nos animais.

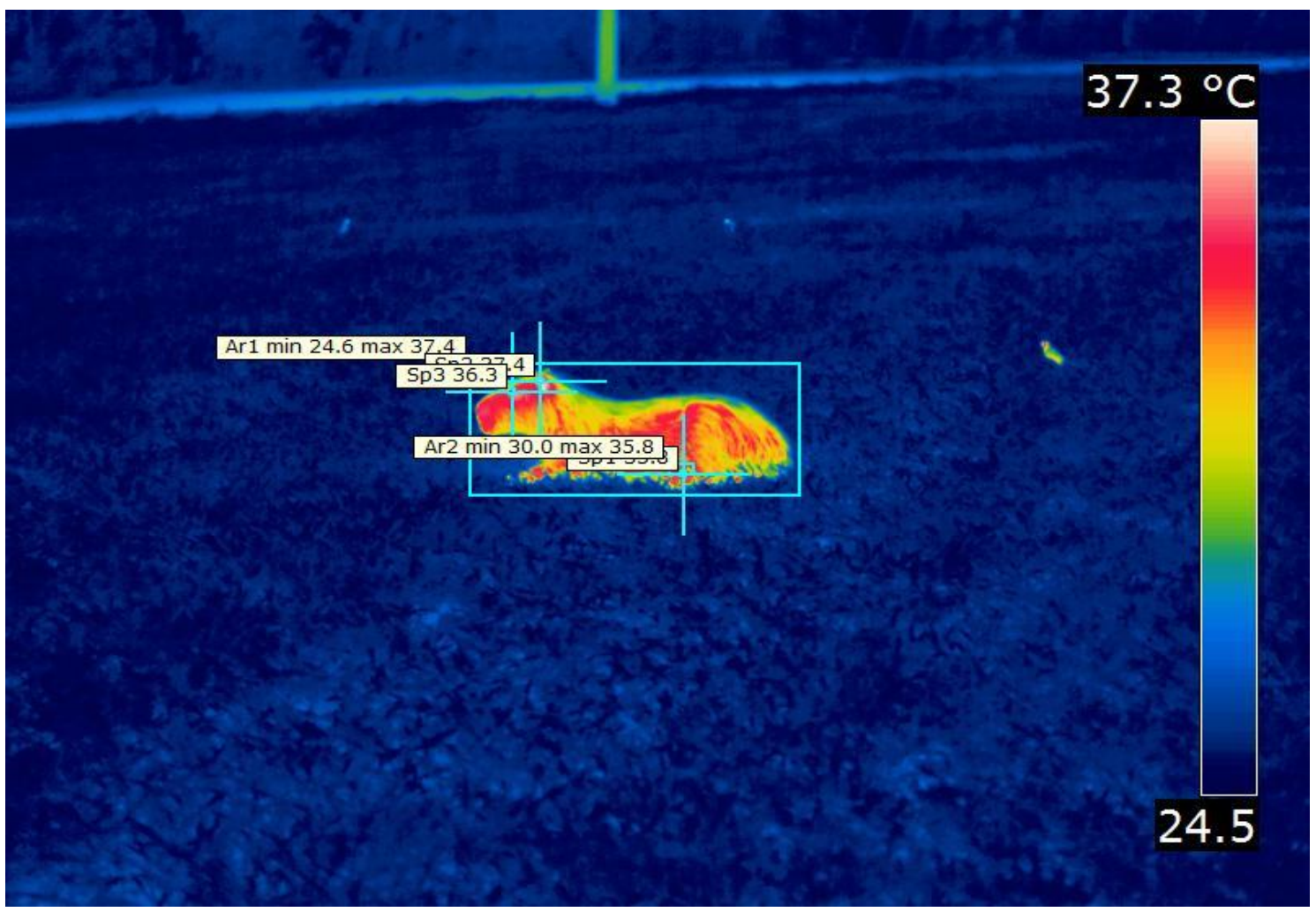

Figura 2. Fêmea adulta com aumento de temperatura na região abdominal

Os filhotes apresentaram uma temperatura maior comparada aos adultos (Tabela 5), tanto em machos como fêmeas e isto pode ser sugerido por apresentarem um metabolismo maior quando comparado aos adultos, acrescendo sua demanda energética e sua produção de calor.

Tabela 5. Média da temperatura filhotes de capivara do perímetro urbano de Campo Grande, MS

\begin{tabular}{lccc}
\hline & Mínima $\left({ }^{\circ} \mathrm{C}\right)$ & Máxima $\left({ }^{\circ} \mathrm{C}\right)$ & Média $\left({ }^{\circ} \mathrm{C}\right)$ \\
\cline { 2 - 3 } Imagem & 23,4 & 36,7 & 28,4 \\
Ar1 - Área animal & 24,0 & 36,7 & \\
Sp1 - Olho & 35,8 & & \\
Sp2 - Ouvido & 36,2 & & \\
\hline Ar & Ár
\end{tabular}

$\mathrm{Ar}-$ Área total do animal; $\mathrm{Sp}$ - ponto representado nos animais.

Um dos filhotes observados apresentava uma claudicação no membro posterior direito e quando analisada a termografia apresentou um aumento de temperatura significativo na região quando comparado com o resto do corpo assim como na Figura 3. De acordo com Silva et al. (2013) o aumento da temperatura é indicativo de reações patológicas indicando inflamação e vasodilatação.

Com a termografia foi possível identificar animais que estavam em matas por diferença de temperatura ambiente e local, sendo assim possível localização de animais em matas fechadas e locais de difícil acesso para que seja feito algum manejo ou contagem dos animais (Figura 4). Também sendo 
possível contagem de animais em um lote para controle (Figura 5) e identificação de macho e fêmea de acordo com a incidência de temperatura da glândula supranasal (Figura 6).

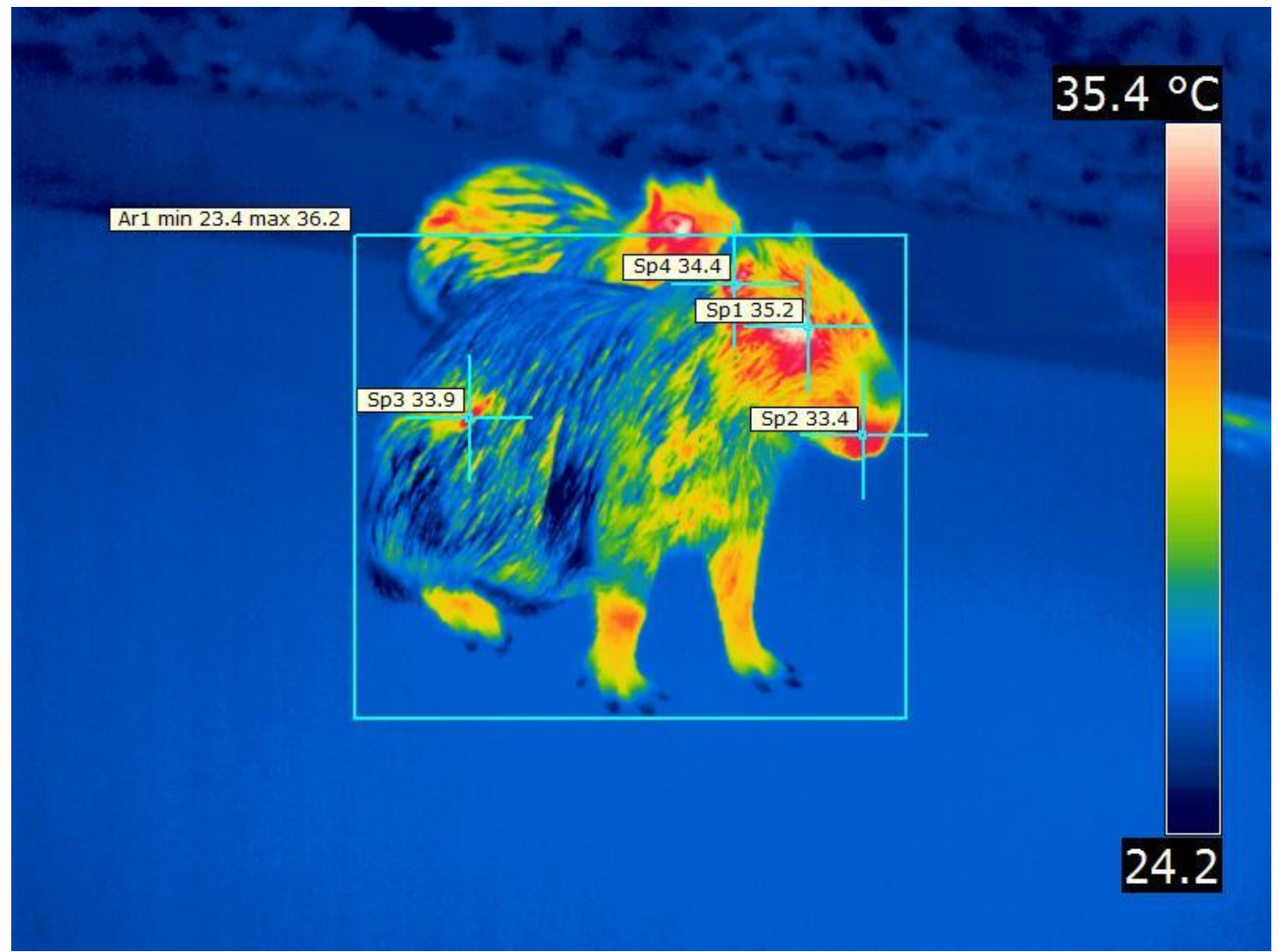

Figura 3. Filhote que apresentava claudicação no membro posterior direito com aumento de temperatura local

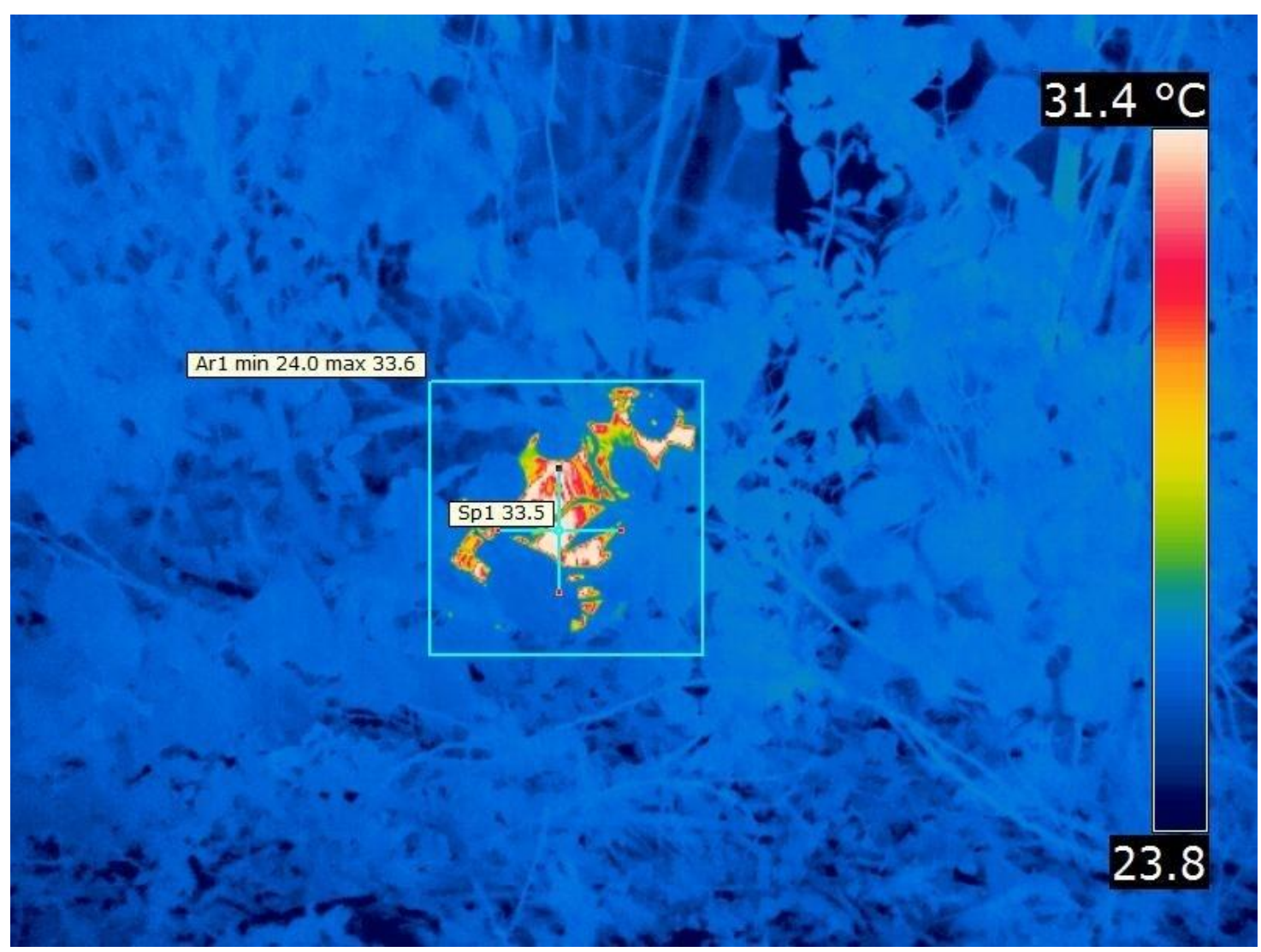

Figura 4. Termografia de animal dentro da mata. 


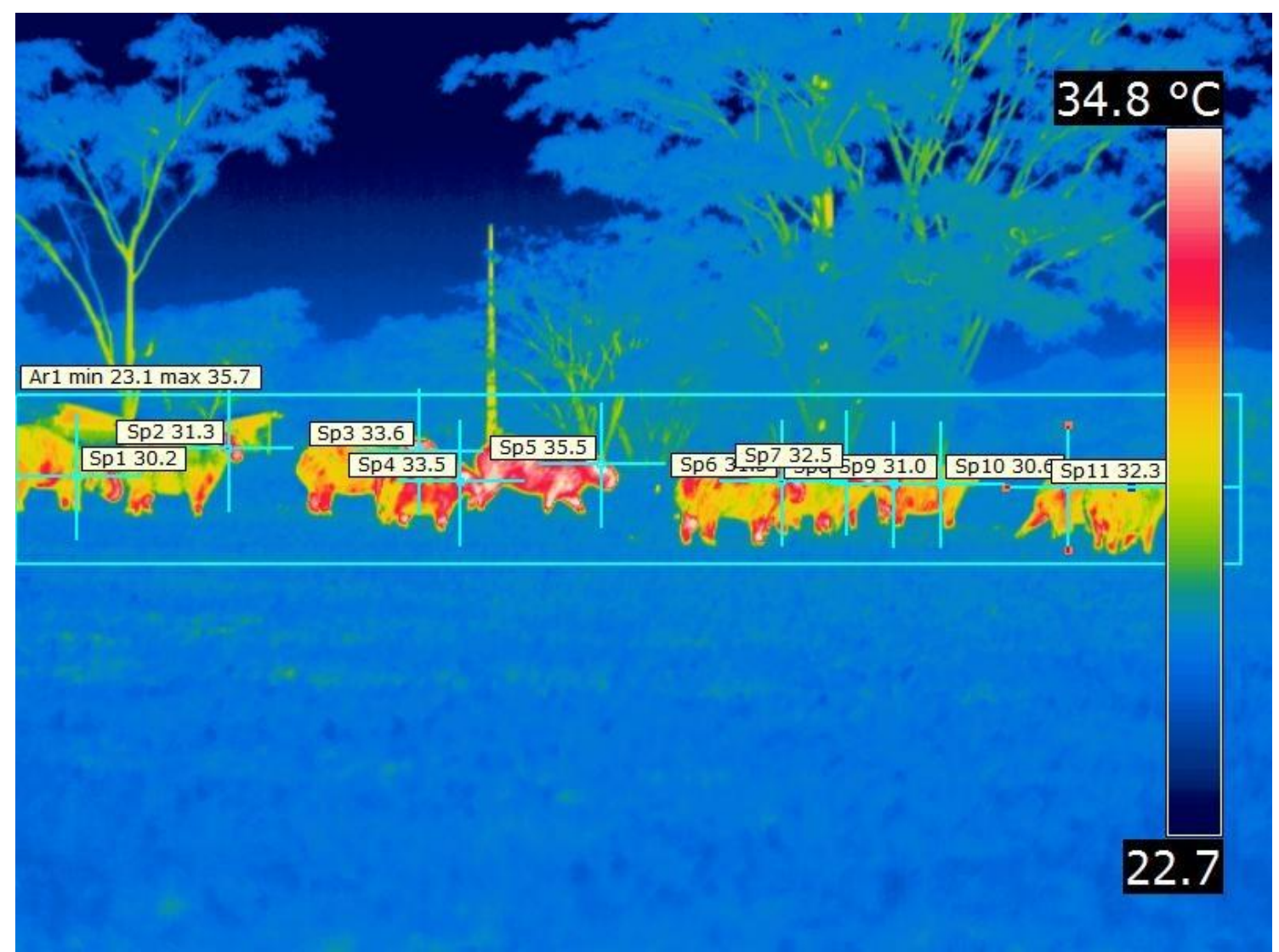

Figura 5. Contagem de animais por lote com uso da termografia em infravermelho.

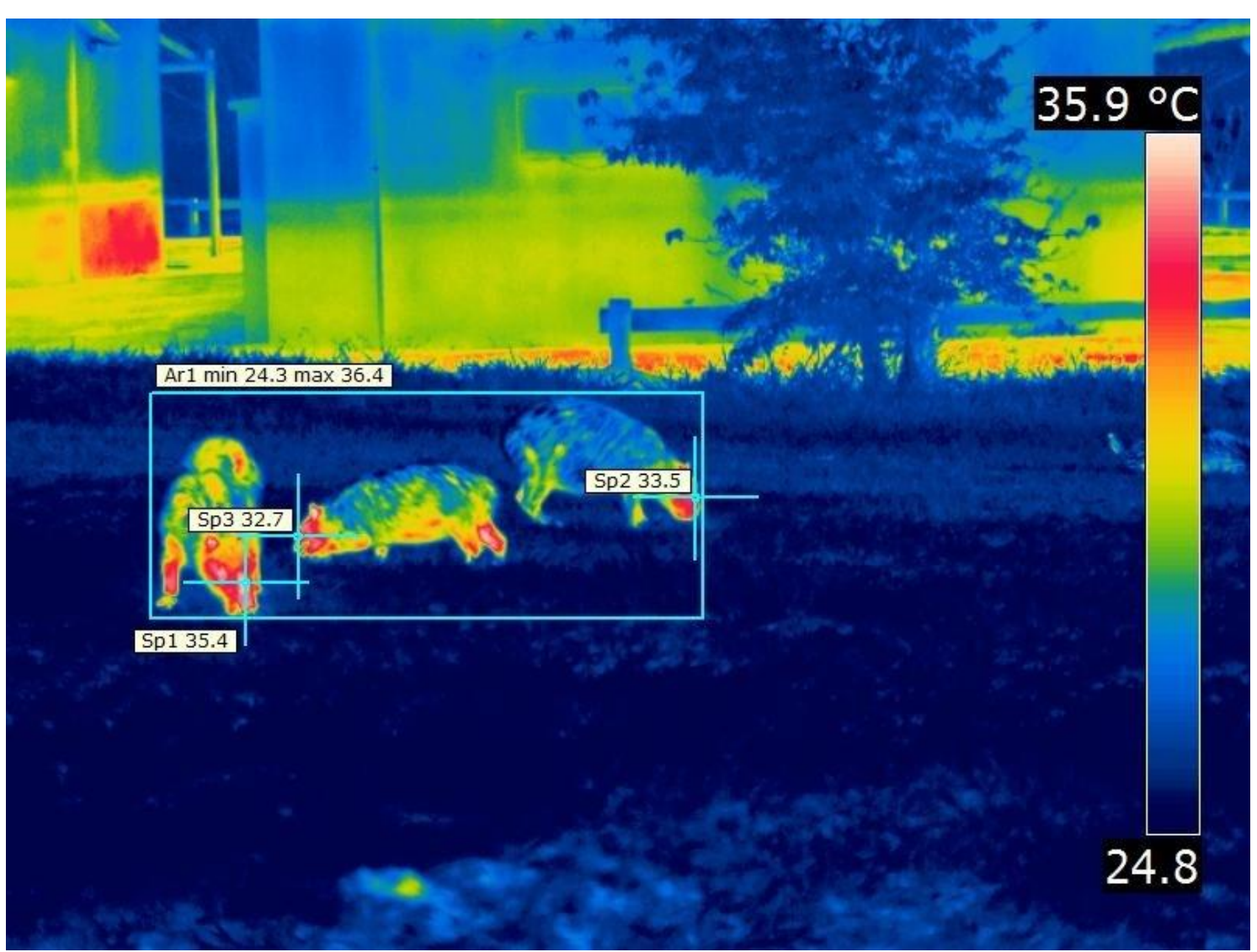

Figura 6. Contagem de animais por lote e separação de macho e fêmea com uso da termografia em infravermelho. 


\section{Conclusão}

A termografia ainda é pouco utilizada quando relatada em medicina veterinária e principalmente envolvendo animais silvestres. Este trabalho mostra a eficiência da metodologia para diminuir o manejo com esses animais, não alterando o seu bem-estar. Com isso, verifica-se que as imagens podem nos auxiliar para identificação de patologias, número de animais em um lote, procura de animais em locais de difícil acesso e classificação de macho ou fêmea, nos auxiliando tanto em exames clínicos individuais como análises em grupo.

\section{Referências bibliográficas}

Alho, C. J. R., Campos, Z. M. S. \& Gonçalves, H. C. (1987). Ecologia de capivara (Hydrochaeris hydrochaeris, Rodentia) do Pantanal: I-habitats, densidades e tamanho de grupo. Revista Brasileira de Biologia, 47(1/2):87-97.

Alho, C. J. R. \& Cleber, J. (1986). Criação e manejo de capivaras em pequenas propriedades rurais (Vol. 1). Brasília, Brasil: EMBRAPA.

Batista, J. S., Bezerra, F. S. B., Agra, E. G. D., Calado, E. B., Godói, R. M., Rodrigues, C. M. F., . . . Soto-Blanco, B. (2009). Efeitos da contenção física e química sobre os parâmetros indicadores de estresse em catetos (Tayassu tajacu). Acta Veterinaria Brasilica, 3(2):92-97.

Brioschi, M. L., Macedo, J. F. \& Macedo, R. A. C. (2003). Termometria cutânea: novos conceitos. Revista Vascular Brasileira, 2(2):151-160.

Centurion, S. R., França, A. F. S., Bezerra, B. B., Felix, G. A. \& Piovezan, U. (2016). Temperatura superficial de bovinos considerando áreas com e sem a presença de pelos. Paper presented at the Embrapa Pantanal, Santa Maria, Rio Grande do Sul, Brasil.

Digiovani, D. B. (2014). Termografia infravermelha como ferramenta diagnóstica para detecção da mastite subclínica bovina. Master of Science, Iniversidade do Norte do Paraná, Londrina, Paraná, Brasil.

Ferreira, K. D., Ávila Filho, S. H. \& Fernanda, J. (2016). Termografia por infravermelho em medicina veterinária. Enciclopedia Biosfera, 131298-1313.

Furlan, S. A. \& Milko, S. S. (2008). Animais da Amazônia. São Paulo, Brasil: Editora Horizonte.

Lahiri, B. B., Bagavathiappan, S., Jayakumar, T. \& Philip, J. (2012). Medical applications of infrared thermography: a review. Infrared Physics \& Technology, 55(4):221-235.

Lima, L. R., Barbosa, J. A. D., Souza Jr, J. B. F., Ricarte, A. R. F., Santos, E. A., Costa, L. L. M. \& Oliveira, M. F. (2014). Aplicação da termografia infravermelha para determinar os padrões de temperatura da bolsa escrotal de catetos (Tayassu tajacu Linnaeus, 1758). Journal of Animal Behaviour and Biometeorology, 2(3):85-89.

Mikail, S. (2010). Termografia: diagnóstico através da temperatura. Nosso Clínico, 13(74):20-24.

Roberto, J. V. B. \& Souza, B. B. (2014). Utilização da termografia de infravermelho na medicina veterinária e na produção animal. Journal of Animal Behaviour and Biometeorology, 2(3):73-84.

Silva, M. H., Nascimento, J. C. S., Vanderley, S. R., Sauthier, J. T., Bandeira, J. \& Franco, L. O. (2013). Infravermelho na ciência forense. Instituto Geral de Perícias. Recife, Brasil.

Recebido: 13 de fevereiro, 2019.

Aprovado: 4 de março, 2019.

Publicado: 27 de março, 2019.

Licenciamento: Este artigo é publicado na modalidade Acesso Aberto sob a licença Creative Commons Atribuição 4.0 (CC-BY 4.0), a qual permite uso irrestrito, distribuição, reprodução em qualquer meio, desde que o autor e a fonte sejam devidamente creditados. 